\title{
Additive Focus Adverbs in Canonical Word Orders \\ A Corpus-based Study of It. anche, Fr. aussi and E. also \\ in Written News*
}

Anna-Maria De Cesare (Basel)

\begin{abstract}
The goal of this paper is to offer a cross-linguistic analysis of the most commonly occurring additive focus adverbs used in Italian, French and English - namely anche, aussi and also on the basis of a corpus of written texts. The corpus used in this paper consists of comparable online news in Italian, French and English amounting to approximately 750000 words. In line with previous findings, our results show that there are important quantitative and qualitative differences between It. anche, Fr. aussi and E. also. These items differ not only in their overall frequency of use but also in the specific syntactic configurations in which they occur when they associate with the Subject of a canonical sentence. These differences are partly enhanced by the fact that this paper concentrates on a non-prototypical configuration, i. e. on the cases in which the canonical Subject coincides with a new entity while the Predicate is maintained.
\end{abstract}

\section{Introduction}

In a number of cross-linguistic studies on Additive Focus Adverbs (henceforth AFAs) which form a subgroup of Focus Adverbs (henceforth FAs ${ }^{1}$ ) and include, among many others, Italian anche and pure, French aussi and également, Spanish también, English also and too, German auch and Dutch ook - it has been shown that, albeit sharing a bundle of basic semantic (expression of added element) and syntactic properties (mobility), these adverbs can still vary quite significantly at least in terms of their frequency of use and syntactic distribution. A first set of examples showing the semantic and syntactic similarities between the most commonly occurring AFAs used in Italian, French and English is given in (1):

\footnotetext{
* This study has been written with the financial support of the Swiss National Science Foundation (project Italian Constituent Order in a Contrastive perspective, funded by the SNSF grant PP00P1_133716/1). I would like to thank Cecilia Andorno as well as Davide Ricca for their helpful comments on a previous draft of this paper.

${ }^{1}$ In the literature, we find many other labels for the class in which we are interested. Among the most frequently occurring terms used in English, we can mention focusing adverbs, focus/focusing particles and scope particles (an overview of the labels used in the literature on Italian, French and English is offered in De Cesare, in press). 
(1)
It. Stella ha anche letto Shakespeare.
Fr. Stella a aussi lu Shakespeare.
E. Stella has also read Shakespeare.

In the literature available to date, AFAs have been described on the basis of very diverse bodies of language data. Consequently, the results currently available cannot be directly compared (neither intra- nor cross-linguistically). Some contrastive-comparative studies are based on spoken, elicited speech productions (cf. for instance Benazzo/Andorno 2010 on It. anche, Fr. aussi and G. auch and Dimroth et al. 2010 on the same set plus D. ook); other studies use corpora of heterogeneous sources, including both spoken and written material, without making a clear distinction between the two mediums (cf. Borreguero Zuloaga 2011 on It. anche and Sp. también; to some extent, see also De Cesare/Borreguero Zuloaga 2014 on It. anche, Fr. aussi and Sp. también); yet other studies use comparable, i. e. original texts, or parallel corpora, i. e. original texts and their translations (cf. Blumenthal 1985, who describes Fr. aussi and G. auch on the basis of journalistic, academic and literary texts, and Lauwers 2003, 2006, who analyzes Fr. aussi and D. ook among others on the basis of a parallel corpus Dutch-French, the nature of which is not specified). ${ }^{2}$

The goal of this paper is to offer a cross-linguistic analysis of the most commonly occurring AFAs used in written Italian, French and English - namely It. anche, Fr. aussi and E. also -, by focusing on the configuration in which they have scope over the Subject of a canonical sentence, i. e. the Subject placed in preverbal position (as in anche Stella legge Shakespeare/Stella also reads Shakespeare). The corpus used in this study is a sub-part of the ICOCP corpus, a collection of comparable online news written in Italian, French and English amounting to approximately 750000 words collected during the last quarter of 2011 (cf. De Cesare et al. 2014). In respect to other studies, our analysis differs in at least three ways: (i) it compares three AFAs not yet compared before (It. anche and Fr. aussi have been compared mainly to G. auch); (ii) it is based on a corpus of naturally occurring texts (as opposed to invented examples and/or elicited data); and (iii) it is based on a corpus of comparable functional (i. e. non-literary) written texts.

In line with previous findings, our results show that there are important quantitative and qualitative differences between It. anche, Fr. aussi and E. also. First, they differ in both their overall frequency of use and occurrence in canonical word orders; second, they are found in partly different syntactic configurations. Specifically, when they focus on the Subject of a canonical sentence, the three AFAs appear in distinct sentence slots and with different scope extensions. While E. also takes wide scope and always needs the context to narrow down its association with the Subject, It. anche and to some extent Fr. aussi are used in configurations

\footnotetext{
2 The same heterogeneity in the data taken into account can be observed in monolingual studies on anche, aussi and also, respectively. As far as Italian is concerned, while La Forgia 2006 bases her analysis of anche on both literary (plays from the second half of the $20^{\text {th }} \mathrm{C}$.) and journalistic texts (corpus: la Repubblica), De Cesare's $2004 \mathrm{a} / \mathrm{b}$ and 2008 studies anche on the basis of written texts mainly including journalistic and academic prose. The same can be observed for English also: Fjelkestam-Nilsson 1983 bases her analysis of the AFA on both the Brown (a corpus of American written texts published in 1961) and the Lancaster-Oslo/Bergen corpus (including British texts), while Gast 2006 as well as Ureña Goméz-Moreno 2006 use the British National Corpus (BNC) to analyzes also in written and oral texts belonging to different registers.
}

ISSN 1615-3014 
in which it is unequivocally the Subject that functions as their focus. However, It. anche and Fr. aussi are found in completely different configurations. While It. anche always appears before the canonical Subject, Fr. aussi occurs after the finite verb, most often in a special syntactic construction involving the reduplication of the Subject by means of a full pronoun (Stella ... elle aussi... 'Stella... she also...').

Our findings suggest that there are important differences not only between the two Romance AFAs and the English one, but also between the two Romance AFAs themselves. This is partly due to the fact that the specific semantic and syntactic configurations in which we are interested - namely the case in which our AFAs focus on the canonical Subject, as opposed to the Predicate or part of it - are not prototypical and thus that in these configurations the differences between the AFAs taken into account are somewhat enhanced. Typically, languages have to resort to more differentiated strategies when they have to tackle nonprototypical configurations.

This paper is organized as follows: $\S 2$ offers a brief semantic and syntactic characterization of the most commonly occurring AFAs in Italian, French and English; $\S 3$ describes the options available to these AFAs to focus on the Subject of a canonical sentence; $\S 4$ presents the results of our empirical study, firstly by describing the overall frequency of use of anche, aussi, also in our corpus of online news and, specifically, in canonical sentences, and secondly by analyzing the contexts in which these AFAs focus on the canonical Subject; $\S 5$ summarizes our main findings and points to some open questions to be addressed in future research.

\section{Semantic and syntactic properties of Additive Focus Adverbs}

Additive Focus Adverbs (AFAs) are a subclass of Focus Adverbs (FAs) ${ }^{3}$ that represent a relatively closed set of expressions sharing a group of central semantic and syntactic properties (cf. König 1991, 1993). Not all the AFAs share all the core properties of the class (see De Cesare in press). ${ }^{4}$ Consequently, in this study we only focus on the most typical AFAs used in Italian, French and English, namely anche, aussi and also.

\subsection{Semantic properties: additive presupposition, domain of association and scope}

From a semantic point of view, AFAs are additive expressions. They presuppose at least one alternative to the element on which they focus or, to use a more neutral description, with which they are associated (cf. König 1991: 55 on E. also; Andorno 2000: 67 on It. anche;

\footnotetext{
${ }^{3}$ The term Focus in the label Focus Adverbs refers to the fact that the items belonging to this class are typically used to highlight a piece of information in the sentence in which they occur (cf. Taglicht 1984 as well as Quirk et al. 1985). This aspect is controversial, though, as some scholars prefer to claim that FAs limit themselves to interact with the focused part of the sentence (cf. König 1991; De Cesare 2010) and claim that these forms are sensitive to the presence of a focus that is determined by other linguistic means (in particular prosody in oral communication).

${ }^{4}$ Cf. the following claim by König (1991: 15): "Each class [i.e. English and German FAs, respectively] contains prototypical members which meet many or most of the relevant criteria. [...] In contrast to E. even (just, also), too may only precede the focused element under very specific conditions (cf. Taglicht 1984: 187-188)".
}

ISSN 1615-3014 
Amsili/Winterstein 2012 on Fr. aussi). ${ }^{5}$ In this paper, we call the element with which they are associated, and that is to be interpreted as added, domain of association (henceforth DA; on this concept, cf. Dimroth/Klein 1999; Ricca 1999; Andorno 2005: 406). ${ }^{6}$ For instance, in the examples given in (2), It. anche, Fr. aussi and E. also presuppose (3) that, besides Shakespeare, i. e. the constituent that functions as their DA, Stella reads at least something else (the number and nature of the alternatives are defined by the context). ${ }^{7}$ This is the prototypical reading of the three AFAs in configurations such as (2).

(2) It. Stella ha anche letto Shakespeare.

Fr. Stella a aussi lu Shakespeare.

E. Stella has also read $\underline{\text { Shakespeare. }}$

(3) 'Stella read something else as well.' (Presupposition)

Moreover, we will use the term scope to refer to the sum of potential DAs an AFA can have in a given sentence position (in line with Ricca 1999: 146, on the basis of Dimroth/Klein 1996: 80). In example (4), the scope of anche coincides with the whole sentence Stella ha letto Shakespeare 'Stella read Shakespeare' because, depending on the context, in the configuration given in (4), It. anche can be associated to the Direct object alone (4a), to the whole VP (4b), to the Subject (4c) or to the verb (4d):

(4) Stella ha anche letto Shakespeare.
a. Stella ha anche letto Shakespeare.
b. Stella ha anche letto Shakespeare.
c. Stella ha anche letto Shakespeare.
d. Stella ha anche letto Shakespeare.

On the basis of example (4), we can also observe that an AFA occurring in wide scope position allows for multiple interpretations of its DA only when the sentence in which the AFA appears is taken out of context. ${ }^{8}$ It is clear that, both in oral and written communication, the context helps identifying the correct interpretation (cf. Fjelkestam-Nilsson 1983: 8).

Further, we will distinguish two positions in which an AFA can occur: a wide and a narrow scope position. ${ }^{9}$ In this paper, we consider that an AFA occurs in a wide scope position when

\footnotetext{
5 What is asserted in sentences containing an AFA seems to be more controversial. While it is generally recognized that the asserted part of the proposition containing an AFA is the value expressed by the AFA's associate (cf. Andorno 2000: 67), some studies claim that a proposition containing an AFA does not have any asserted content whatsoever (see Amsili/Winterstein 2012). We leave this question open.

6 Here, too, we find many other terms in the literature: E. focus (in König 1991:18), E. added constituent (in Gast 1996); Fr. noyau 'nucleus' (in Nølke 1983); It. portata 'scope' (Andorno 2008).

${ }^{7}$ In the examples given in this paper, the AFA is highlighted in bold and the DA is underlined.

${ }^{8}$ Cf. the observation made in Quirk et al. (1985: 605), "When it comes to writing down such sentences [i. e. as Stella has also read Shakespeare] within the normal conventions of English punctuation [i. e., without the capital letters indicating focal information], [...] we see at once that the identification of the focused item is quite uncertain".

9 The label wide scope is translated from the German weitem Skopus used for instance in Dimroth/Klein (1996: 93). Note that there is another definition of scope in the literature: for König 1991, for instance, the scope
} 
its DA coincides with more than one sentence constituent (the Subject, an Object and/or the whole VP), as in (4) above. In this case, the exact DA of the AFA is not defined syntactically, by the position of the AFA alone, but by the context. ${ }^{10}$ By contrast, an AFA occurs in a narrow scope position when it is unequivocally associated with a specific sentence constituent (the Subject, an Object or the whole VP). This is for instance the case in the Italian example given in (5):

Anche Stella ha letto Shakespeare.

a. Anche Stella ha letto Shakespeare.

In respect to their DA, AFAs can occur in different positions: they can be adjacent (as in (5a)) or non-adjacent (4a) to it. Moreover, they can be used as pre-, post- or intramodifiers, as in $(4 a),(4 c)$ and $(4 b)$, respectively. ${ }^{11}$

\subsection{Syntactic properties of Additive Focus Adverbs}

As shown in examples (4) and (5) on the basis of Italian, most commonly occurring AFAs occur in different sentence slots depending on the nature of their DA and scope. The "positional variety" (cf. König 1991: 10) of these forms is a central property documented cross-linguistically. The abstract configurations given in (6) to (8) on the basis of different types of canonical sentences show that It. anche, Fr. aussi and E. also can occur in all the major sentence slots. ${ }^{12}$ They can appear before the finite verb (as in slots I and II) and after the finite verb (as in slots III to V):

(6) I Gianni II ha III preteso IV il rimborso del viaggio V

(adapted from Andorno 2000: 51)

'John asked for the trip reimbursement'

(7) I Marie II a III dormi IV (Perrin-Naffakh 1996: 140)

'Marie slept'

(8) I Leo II danced III with Lea IV (adapted from Ureña Gómez-Moreno 2009: 91)

Several general remarks, which will be further developed in the rest of the paper, ought to be made here. First, anche, aussi and also cannot all occur in these slots and function as AFAs. In slot I, aussi and also function as discourse connectives. Second, there are slots that are more register-specific than others. For instance, the last slot in the Italian configuration

is "the domain within which a focus marker is effective" (cf. Taglicht 1984: 9, cit. in Andorno 2000: 73-75). In other words, in König's view the scope of also coincides with an open proposition (the scope of also in Stella also read Shakespeare is Stella read $x$ ).

10 In spoken communication the correct interpretation of examples such as (4) strongly relies on prosodic cues. The DA of the AFA is determined by accentuating the DA (as in 4c), the AFA or both (cf. Perrin-Naffakh 1996: 145-147 on Fr. aussi; Quirk et al. 1985: 605 for E. also; also see Ureña Gómez-Moreno 2009, chap. 3, p. 88 for a more skeptical view). As we do not take into account spoken data here, we will not describe prosodic cues any further (on this issue, we refer to Andorno/Turco, this issue).

11 The terms pre-, post- and intramodifiers are borrowed from Ureña Gómez-Moreno 2009.

12 For a finer analysis of the syntax of Fr. aussi, we refer to Nølke 1983; Perrin-Naffakh 1996 and Lauwers 2003, 2006; on It. anche, see, among others, Andorno 1999, 2000; and on E. also, cf. Huddleston/Pullum 2002 as well as Fjelkestam-Nilsson 1983 and Ureña Gómez-Moreno 2009 (in part. chap. 3). 
(i. e. V in ex. (6)) is generally considered as being typical of unplanned, spontaneous speech. Third, all the slots are not associated to the same scope. Finally, and this is what we are mainly interested in, the AFAs anche, aussi and also can modify the canonical preverbal Subject from almost all the sentence slots. However, some configurations are clearly preferred over others across the three languages.

\section{Additive Focus Adverbs with the canonical Subject as domain of association}

In this paper, we only consider the cases in which It. anche, Fr. aussi and E. also occur in canonical sentences, i. e. in clauses with SV/SVO/SVOO word orders, in which $\mathrm{S}$ refers to the Subject, V to the Verb (as we will see in more details below, the verb can be simple or complex and, in Italian, the Subject can be implicit), and $\mathrm{O}$ to one or more arguments of the verb (Direct object, Indirect object, Prepositional object etc.). Specifically, we focus on the case in which it is the Subject of a canonical sentence that ought to function as the AFA's DA. ${ }^{13}$ This non-prototypical configuration has been discussed in other studies already. In the papers written by the members of the Langacross project (cf. Andorno 2008; Benazzo/Andorno 2010: 100 and Dimroth et al. 2010), this configuration is exemplified on the basis of discourse sequences such as (9). What is special here is that the AFA "highlight[s] a new entity [the referent denoted by the Subject, i. e. Stella] for which the previous mentioned situation holds" (Benazzo/Andorno 2010: 98). In other words, while the Subject coincides with a new entity, the Predicate is maintained.

(9) [Eva ha letto Shakespeare.] Anche Stella ha letto Shakespeare.

Lit. '[Eva read Shakespeare.] Also Stella read Shakespeare.'

In the next sections, we will describe the possible configurations in which It. anche, Fr. aussi and E. also take the canonical Subject as their DA. This description summarizes the claims made in the literature on the basis of invented or elicited examples and/or of authentic language data (extracted from corpora of spoken or written texts).

\subsection{Anche, aussi and also occurring before the finite verb}

\subsubsection{Anche, aussi and also pre-adjacent to the canonical Subject}

In Italian, when the Subject functions as its DA, anche is generally placed directly in front of it, as shown in example (10). In this case, anche can only have the Subject as its DA.

(10) Anche Gianni ha preteso il rimborso del viaggio.

Lit. 'Also Gianni asked for the reimbursement of the trip.'

The narrow scope position of anche (cf. (10)) is available neither in French (cf. PerrinNaffakh 1996; Lauwers 2003: 9) nor in English (cf. Quirk et al. 1985: 609; Ureña GómezMoreno 2009: 120). Examples such as the following two are thus ruled out. This claim is also confirmed empirically for English. In a collection of 1738 instances of also extracted from a

\footnotetext{
13 For the sake of simplicity, we will not consider the cases in which AFAs focus on a sub-part of the Subject constituent (such as an adjective).
} 
corpus of British and American written texts, Fjelkestam-Nilsson (1983: 29) does not find a single occurrence of examples such as (12):

(11) *Aussi Jean est parti. (Lauwers 2003: 9)

Lit. 'Also Jean left.'

(12) *Also John was sitting on her lap. (Ureña Gómez-Moreno 2009: 120)

Fjelkestam-Nilsson (1983: 29) further observes that there is in fact one configuration in which also occurs in a pre-adjacent position to the Subject and has narrow scope over it. This is the case when the Subject that functions as also's DA is part of a coordinated construction, as shown in the following example:

(13) He and also Mr Cowley and Mr Warren have fallen to the temptation which besets many of us to read into our authors Nathaniel Hawthorne (Brown corpus, cit. in Fjelkestam-Nilsson 1983: 29)

Thus, what comes out is that also is blocked in initial position of a canonical sentence starting with the Subject. The reason usually proposed to explain this restriction is that in initial position also is associated to another function. In initial sentence position, also functions as additive connective (or conjunct) and can be compared to 'in addition' and 'moreover' (cf. for instance Ureña Gómez-Moreno 2009):

(14) In only two ways could women ever assert power in any public fashion. On one day in the year they were allowed to dress as men, tend the cattle, drink beer in a masculine fashion [...]. Also [= In addition/Moreover] any woman, if possessed by the spirits of the dead ancestors, could become a diviner - usually called in lay description 'a witchdoctor'. (Fjelkestam-Nilsson 1983: 29)

A similar claim can be made about Fr. aussi. When it appears in clause initial position, it functions as discourse connective. Differently than E. also, though, Fr. aussi functions as consecutive (Perrin-Naffakh 1996: 141; Blumenthal 1985: 150) or concessive connective (cf. De Cesare/Borreguero Zuloaga 2014):

(15) Il pleut; aussi Paul reste à la maison (Perrin-Naffakh 1996: 141)

'It's raining; so/therefore Paul stays at home'

\subsubsection{Anche, aussi and also post-adjacent to the canonical Subject}

In the literature on Italian FAs, it is sometimes claimed that anche can also have the canonical Subject as its DA when it directly follows the Subject (cf. La Forgia 2006: 360; Andorno 2005: 409), as in (16). According to a perception test reported in Andorno 2008, however, this configuration turns out to be odd or even unacceptable to $30 \%$ of informants. The fact that a configuration such as (16) is perceived as less natural than (10), in which anche directly precedes the Subject, can be explained by the fact that the "principle of right scope", i. e. of finding anche's DA to its right, is violated (cf. Andorno 2008). This configuration is perceived as more marked surely also because of its prosodic pattern. With respect to a configuration such as (10), in (16) it is necessary to stress the AFA (cf. small capitals on anche). 
(16) Gianni ANCHE ha preteso il rimborso del viaggio.

'Gianni also has pretended the reimbursement of the trip.'

Turning to French, it can be observed that aussi unequivocally takes the Subject as its DA when it occurs immediately after the Subject (Perrin-Naffakh 1996: 143), i. e. is placed between the Subject and the VP, as in (17). Interestingly, however, it has been claimed that French sometimes avoids this configuration (Lauwers 2003: 9, note 1714). Thus, instead of sentences such as ' $\underline{\mathrm{S}}$ aussi $\mathrm{V}_{\text {fin }}(\mathrm{O})$ ', French prefers the configuration ' $\underline{\mathrm{S}} \mathrm{V}_{\text {fin }} \operatorname{aussi}(\mathrm{O})$ ', in which aussi appears in postverbal position, as in (18). With respect to (17), though, in (18), aussi occurs in a position in which different DAs could be selected: depending on the context, also can operate on the entire VP or on the Subject).

(17) Jean aussi est parti. (Lauwers 2003: 9)

'John too left.'

Jean est aussi parti.

'John has also left.'

As far as English is concerned, it should first be observed that also is absolutely natural when placed between the Subject and the finite verb (henceforth $V_{\text {fin }}$ ), i. e. when occurring in medial position (Quirk et al. 1985: 609). According to the corpus-based results reported in Fjelkestam-Nilsson 1983, however, also is part of the configuration ' $\underline{\mathrm{S}}$ also $\mathrm{V}_{\text {fin }}$ ' in only $25 \%$ of the cases. It should further be observed that, in this position, also can be associated to different DAs (cf. Huddleston/Pullum 2002: 593). It can be associated to the Subject, as shown in (19), but also to the Object or the whole VP (V+O), as in (20):

(19) The warm night air had quite gone to his head, and had Araminta not been quite so very unattainable, doubtless other parts also would have shared his intoxication. (Ureña Gómez-Moreno 2009: 142)

(20) He also expanded and modernized the radio system with a central control station. (Brown corpus; cit. in Fjelkestam-Nilsson 1983: 32; a broader context of occurrence is lacking here)

\subsection{Anche, aussi and also occurring after the finite verb}

\subsubsection{Anche, aussi and also post-adjacent to the finite verb}

When It. anche, Fr. aussi and E. also appear after the finite verb, as in (21) to (23), they can associate with almost any constituent of the canonical sentence. Their DA can coincide with the Subject, with the whole VP or with the Direct object only. The examples given below also show that, in this position, the three AFAs can function either as premodifiers (cf. (21c)),

\footnotetext{
14 This observation is based on the translation of the Dutch AFA ook in French. In a corpus of 43 instances in which ook is found before the Subject (note that the Dutch AFA cannot occur after the Subject and have scope over it) and is translated by aussi, Lauwers finds 17 occ. with aussi placed after the finite verb. Hence, in his data, the configuration ' $\underline{\mathrm{S}}$ aussi $\mathrm{V}_{\text {fin' }}$ ' is avoided in nearly half of the cases ( $40 \%$ of the cases).
} 
postmodifiers (as in (21a)) or intramodifiers (as in (21b)). Moreover, they can be either adjacent (cf. (21b)) or non-adjacent (as in (21a and c)) to their DA:

(21) Gianni ha anche preteso il rimborso del viaggio. (cf. Andorno 2000: 51)

'Gianni has also pretended the reimbursement of the trip.'

a. Gianni ha anche preteso il rimborso del viaggio.

b. Gianni ha anche preteso il rimborso del viaggio.

c. Gianni ha anche preteso il rimborso del viaggio.

(22) Marie mange aussi une orange. (cf. Perrin-Naffakh 1996: 141)

Lit. 'Marie eats also an orange.'

a. Marie mange aussi une orange.

b. Marie mange aussi une orange.

c. Marie mange aussi une orange.

(23) Jill had also attended the history seminar. (cf. Huddleston/Pullum 2002: 586)

a. Jill had also attended the history seminar.

b. Jill had also attended the history seminar.

c. Jill had also attended the history seminar.

With respect to the options given in $b$ and $c$ of example (21) to (23), the possibility for our AFAs to have the canonical Subject as their DA (option $a$ in the same examples) is less natural and requires additional markings of the configuration. In both Italian and French, we would expect the Subject to be stressed (Perrin-Naffakh 1996: 147). As for English, while the possibility for also modifying the Subject is ruled out by some (cf. Quirk et al. 1985: 60915), it should in fact be considered to be possible. Here, too, we would expect the configuration to be associated with a special prosodic pattern (in English, it is the AFA itself that seem to be the stress carrier: cf. the example Bill has bought a car and Sue has ALSO bought a car, given in Gast 2006: 164). Corpus-based studies even show that the occurrence of also after the verb be is in fact the "normal position in that case [i. e. when also has scope over the Subject]", as it occurs in that position in 55\% of the cases (Fjelkestam-Nilsson 1983: 31). ${ }^{16}$ Here is one authentic example from the traditional paper press:

(24) First the CAR carrying Mr. Dean Rusk, Secretary of State, broke down on the way to the airport. It was pushed off the road and another one was produced, but the party was ten minutes late reaching the airport. Then just as the Presidential jet was about to taxi

15 Cf. the claim made on the basis of the example John could also see his wife from the doorway (Quirk et al. 1985: 605), in which also occurs between a modal verb form and the lexical verb. According to the authors of the grammar, in this sentence slot also "has the choice of focusing the main verb [see], another part of the predication [his wife or from the doorway], or the whole predication [see his wife from the doorway]" (Quirk et al. 1985: 605).

16 This finding is supported by other corpus-based studies. In Ureña Gómez-Moreno 2009 it is claimed that when also is associated to the Subject it is usually placed after the main verb (cf. the brief observations made on pp. 120-122). 
on to the runway another group of the party rushed on to the tarmac and a packet of newspapers was also thrown aboard. (Lancaster-Oslo/Bergen corpus; reportage; ex. cit. in Fjelkestam-Nilsson 1983: 31; here, we have provided more context)

\subsubsection{Anche, aussi and also in sentence final position}

When they occur in sentence final position, after the finite verb and one or more complements (of the verb), It. anche, Fr. aussi and E. also generally select as DA the constituent occurring immediately before them. The possibility of taking the canonical Subject as their DA, as in (25) to (27), is a rather marked one. The Italian example given in (25) is odd at best (on these issues, we refer to the observations made in Andorno 1999, 2000, 2008 for Italian; PerrinNaffakh 1996: 144 and Lauwers 2003 for French; Taglicht 1984: 186 and Huddleston/Pullum 2002: 593 for English):

(25) Volevo spedire una lettera a Domenico... te lo dico, se tu volevi scrivere qualcosa anche (Andorno 2008; authentic example, spontaneous speech)

Lit. 'I wanted to send a letter to Domenico... I tell you, if you wanted to write something also.'

(26) Paul mange une orange. Marie mange une orange aussi.

(Perrin-Naffakh 1996: 141, 144)

'Paul eats an orange. Marie eats an orange also.'

(27) We plan to visit Paris also (Huddleston/Pullum 2002: 593)

\subsection{Anche and aussi in configurations with Subject reduplication}

In French and Italian, another strategy is available to unequivocally signal that the DA of aussi/anche is the Subject of the canonical sentence. This strategy consists of reduplicating the grammatical Subject in the form of a full pronoun (e. g. Fr. lui/elle, It. lui/lei), on which aussi/anche operates (cf. the observations in Perrin-Naffakh 1996; Lauwers 2003, and Benazzo/Andorno 2010 for French; Andorno 2008 and again Benazzo/Andorno 2010 for Italian). This special morpho-syntactic strategy can be described as follows (note that the Subject and the full pronoun are coreferential):

Fr. $\quad$ Subject $_{\mathrm{i}} \ldots \quad$ [full Subject pro ${ }_{i}$ aussi $] \quad$ Stella lit elle aussi.

It. $\quad$ Subject $_{i} \ldots \quad$ [anche full Subject pro $\left.{ }_{i}\right] \quad$ Stella legge anche lei.

As for French, this strategy is very useful in particular when aussi ought to focus on a canonical Subject realized by a clitic pronoun (il/elle) and the sentence is based on a simple verb form (cf. il lit 'he sleeps'). Since the only possible position for aussi in these cases is after the finite verb, ${ }^{17}$ as in (29), and since this position can trigger two interpretations of the adverb's DA, using the strategy based on Subject reduplication (30) provides an unequivocal signal that aussi's associate is the Subject alone:

\footnotetext{
${ }^{17}$ Fr. aussi can of course not follow a clitic Subject (*Il aussi lit); in this case, a full pronoun is required (Lui aussi lit; cf. Perrin-Naffakh 1996: 143).
} 
(29) Il lit aussi. 'He reads too.'

a. Il lit aussi.

b. Il lit aussi.

$\mathrm{Il}_{\mathrm{i}} \operatorname{lit}_{\underline{\mathrm{lui}}} \mathrm{i}_{\mathrm{i}}$ aussi.

Lit. 'He reads he also.' = 'He reads too.'

In French, as well as in Italian, there is in fact another reason to select the configuration with Subject reduplication (cf. Andorno 2008). Configurations such as (31) solve the conflict of having, within the same proposition, a preverbal Subject that functions both as a Topic and a Focus (as in the case anche Stella legge, lit. 'also Stella reads'). This conflict is solved by distributing the two information functions over two distinct NPs: the Topic is associated to the preverbal Subject, while the Focus is associated to the postverbal pronoun preceded (in Italian) or followed (in French) by the AFA.

(31) Stella $\mathrm{T}_{\text {Topic }}$ legge anche lei $\underline{\mathbf{i}}_{\text {Focus. }}$

Lit. 'Stella reads also she.' = 'Stella reads too.'

\subsection{Canonical Subject as domain of association: overview of cross-linguistic options}

The options available to It. anche, Fr. aussi and E. also to take the Subject of a canonical sentence as their DA are summarized in the following table. As we have seen in the previous sections, there are important differences in the acceptability and naturalness of these options (recall again the oddity of option IV in Italian). However, as the judgments provided in the literature do not always converge, we do not mark any of these options as being odd and treat them here as potential alternative configurations. In this table, we also indicate if in a given sentence slot the AFA takes a narrow scope over the canonical Subject (abbreviated NS), i. e. if it only associates with the Subject, or a wide scope (WS), i. e. if it can associate with the canonical Subject as well as other sentence constituents (in this table, options marked as NA are Not Available or only found in very specific constructions). Note that in configurations I and II, the AFA occurs before a finite verb (since no clear distinction is made in the literature between a lexical finite verb and an auxiliary, we will not distinguish this either); that in configurations III and IV the AFA occurs after the finite verb and that in configuration $\mathrm{V}$ the AFA can occupy several sentence slots.

\begin{tabular}{|l|l|l|l|l|}
\hline & & It. anche & Fr. aussi & E. also \\
\hline I & AFA $\underline{S} V_{\text {fin }}(\mathrm{O})$ & NS & NA & NA \\
\hline II & $\underline{\text { S AFA }} \mathrm{V}_{\text {fin }}(\mathrm{O})$ & NS & NS & WS \\
\hline III & $\underline{\underline{S}} \mathrm{~V}_{\text {fin }}$ AFA (O) & WS & WS & WS \\
\hline IV & $\underline{\text { S }} \mathrm{V}_{\text {fin }}$ O AFA & ?WS & WS & WS \\
\hline V & Subject reduplication & NS & NS & NA \\
\hline
\end{tabular}

Table 1: Configurations in which anche, aussi and also have the canonical Subject as DA.

This table shows again that anche, aussi and also can be associated with a canonical Subject in different sentence slots and that there are several slots in which an AFA unequivocally takes the Subject as its DA (NS cases, marked in bold). A fundamental difference between Italian and French, on the one hand, and English, on the other, has to be made, as in English 
there is no slot in which also only operates on the canonical Subject. Also note that, with respect to French aussi, Italian anche has more options to select the sole canonical Subject as its DA (cf. configurations I, II and V).

On the basis of the data given in Table 1, several questions arise. Most importantly, we may wonder how the different configurations in which anche, aussi and also have the Subject as their DA are realized in written texts and if there are preferences for a specific configuration over the others across the three languages. In the next section, we will provide an answer to some of these questions by describing how the AFAs anche, aussi and also are used in a comparable corpus of written journalistic texts.

\section{The Additive Focus Adverbs anche, aussi, also in a corpus of online news}

In what follows, we provide a cross-linguistic analysis of It. anche, Fr. aussi and E. also based on a corpus of authentic written texts belonging to the category of online news. After a brief description of our work corpus and the methodology used in this study ( $§ 4.1)$, we assess the overall frequency of use of anche, aussi and also in the corpus as well as their frequency in canonical word orders ( $\S 4.2)$; in the last part of the section, we describe the configurations in which the three AFAs take the canonical Subject as their DA (§ 4.3).

\subsection{Work corpus and methodology}

The work corpus used in this research has been extracted from the ICOCP corpus, a collection of comparable written electronic news created at the University of Basel as part of a research project in contrastive linguistics (see De Cesare et al. 2014 for an in-depth description of the corpus). Details about the work corpus' composition (in terms of sources used and sections of the news that have been selected) and size are provided in the following table:

\begin{tabular}{|c|c|c|}
\hline Italian & French & English \\
\hline $\begin{array}{c}\text { corriere.it } \\
(75500 ; \text { cronache, economia, } \\
\text { politica })\end{array}$ & $\begin{array}{c}\text { lemonde.fr } \\
(131000 ; \text { actualité, économie, } \\
\text { sport })\end{array}$ & $\begin{array}{c}\text { nytimes.com } \\
(44000 ; \text { sports, technology, } \\
\text { politics })\end{array}$ \\
\hline $\begin{array}{c}\text { repubblica.it } \\
(127000 ; \text { cronaca, economia, } \\
\text { sport, scienze, tecnologia })\end{array}$ & $\begin{array}{c}\text { lefigaro.fr } \\
\text { (132000; politique, sport, } \\
\text { économie })\end{array}$ & $\begin{array}{c}\text { usatoday.com } \\
(16000 ; \text { nation })\end{array}$ \\
\hline $\begin{array}{c}\text { lastampa.it } \\
\text { (40000; politica, cronache) }\end{array}$ & & $\begin{array}{c}\text { theguardian.com } \\
(1870000 ; \text { Uk news, politics, } \\
\text { sport, business, environment, } \\
\text { culture, society })\end{array}$ \\
\hline $\mathbf{2 4 2 5 0 0}$ & $\mathbf{2 6 3 0 0 0}$ & $\mathbf{2 4 7 0 0 0}$ \\
\hline
\end{tabular}

Table 2: Work corpus (comparable online news in Italian, French and English).

We have chosen to work with journalistic prose because the written press is often taken as a model for describing standard written varieties of national languages (cf. for instance Dardano 1994 for Italian). Specifically, journalistic prose can be considered somewhat representative of written national varieties as news articles are based on a variety of written 
sources, such as administrative and bureaucratic texts, legal prose etc. (on this issue, cf. for instance Dardano 2008: 16 and Gualdo 2007: 91, as well as De Cesare et al. 2014). At the same time, it is important to be aware of the fact that online news articles contain a fair amount of reported speech (both direct and indirect). The peculiarity of our corpus can be illustrated on the basis of examples such as (32) and (33), containing two sequences of reported speech (cf. the stretches of text reported in quotation marks), where E. also is found outside (32) and within (33) the reported speech, respectively. Since stretches of direct reported speech cannot straightforwardly be interpreted as being based on authentic spoken material (on this issue, cf. for instance Calaresu 2004 and McLaughlin 2012), we will generally overlook the fact that our AFAs also occur in what is presented as reported speech.

(32) Often, she also said this: "Wondering what is happening to me." (ICOCP, usatoday.com)

(33) Further, he said that such a requirement "can also help reinforce skills like collaboration, organization, planning, etc." (ICOCP, usatoday.com)

In our view, what is crucial to take into account in this study is the main pragmatic function of the texts included in our work corpus, in particular when making predictions on the configurations in which we expect the AFAs anche, aussi and also to occur. Online news belongs to the large and heterogeneous macro-category of informative texts (Combettes/Tomassone 1988) and its main function is to inform citizens belonging to different nations of the most relevant events occurring nationally and internationally (cf., e. g., Lepri 2011). Therefore, these texts ought to be written in a clear fashion, especially if we consider the fact that they have to be easily understood by a broad audience, reading on large as well as small screens (computer, tablet or telephone displays). ${ }^{18}$ From this global pragmatic requirement, it follows that we would at least wish to find our AFAs in configurations in which the interpretation of their DA (in our case the Subject) is straightforward even without taking the context into account.

As for methodology, we assess the frequency of use of It. anche, Fr. aussi and E. also in written, journalistic texts by extracting all the occurrences of the three AFAs in the corpus. The description of the syntactic distribution of these expressions as well as of their scope is then offered on the basis of a sample analysis of 100 occurrences of each AFA. Following the classic definition of AFA found in the literature, included in our frequency count are only the uses of anche, aussi and also that "draw attention to a part of a sentence as wide as the predication or as narrow as a single constituent of an element" (Quirk et al. 1985: 604; cf. also Ricca 1999: 148 for Italian). Excluded from our count are therefore the uses of anche, aussi and also that "draw attention" to a whole sentence, as in (34) to (36), where they function as discourse connectives (these examples show that E. also can be used as additive connective,

\footnotetext{
18 It is often claimed that reading on paper or on a screen is in fact very different. Reading online news is longer and requires more effort (on this issue, cf. Lepri 2011: 31-34). Another fundamental difference to be made here is in terms of the time available to compose the news that will appear in an online edition and in the paper one. Since online news have to be published fairly fast, there is not much time for re-reading the pieces. This would explain why AFAs sometimes occur in ambiguous positions.
} 
Fr. aussi as consecutive connective and It. anche, in the sequence anche se, as concessive connective $\left.{ }^{19}\right)$.

(34) China's Zhang Jilong, the AFC's senior vice-president, has stepped in as the interim president. If bin Hammam's appeals aren't resolved by May 29, the AFC will be bound by its own laws to elect a new leader.

Also, Blatter declined to take a clear stance on renewed calls from Asia to allow the use of Islamic headscarves for female players. FIFA banned the Islamic scarf in 2007 citing safety concerns. (ICOCP, nyt.com)

(35) Le spectre d'un scandale sexuel peut s'avérer fatal à tout candidat à la Maison-Blanche, aussi M. Cain a assuré qu'il n'y avait pas d'autres cadavres dans le placard. (ICOCP, lemonde.fr)

'The spectrum of a sexual scandal can be fatal to every candidate to the White House, so Mr. Cain assured that there weren't other skeletons in the closet'

(36) Da un terremoto ovviamente (che non si è verificato, anche se proprio quel giorno un terremoto ha colpito la Spagna). (ICOCP, corriere.it)

'From an earthquake, of course (that has not happened, even if precisely on that day an earthquake struck Spain).'

Also discarded from our analysis are the uses of Fr. aussi in comparative constructions such as 'aussi + Adj. + que' (equivalent to English so; as... as), illustrated in (37), as well as in constructions in which it has an intensifying value (expressed in English for instance by such), as in (38):

(37) Le dépôt de bilan du groupe, qui emploie environ 2870 personnes, pourrait envoyer une onde de choc sur les marchés mais ses conséquences ne devraient pas être aussi importantes que l'impact de la faillite de Lehman Brothers en 2008. (ICOCP, lemonde.fr)

'[...] but its consequences should not be as important as the impact of Lehman Brothers' bankruptcy in 2008.'

(38) A une époque aussi imprévisible, il [Barack Obama] était peut-être même trop prêt. (ICOCP, lemonde.fr)

'In such an unpredictable time, he was maybe even too ready.'

\subsection{Frequency assessments related to the use of anche, aussi and also}

\subsubsection{Overall frequency of use of anche, aussi and also}

In Table 3 we report the frequency of use of It. anche etc. in our work corpus of online news. Overall, these results confirm what has been observed in other cross-linguistic studies, namely that, although semantically and syntactically similar, the most commonly occurring AFAs do

19 The use of anche as additive connective is very rare in Italian (cf. De Cesare 2004b and De Cesare/Borreguero Zuloaga 2014); the same can be claimed about Fr. aussi (cf. Lauwers 2003, 2006). 
not show up with the same frequency. In the case in point, It. anche is much more frequent than the other two: it is two times more frequent than E. also (380 vs. 162 occ.), and three times more frequent than Fr. aussi (380 vs. 106 occ.). These are interesting results in themselves, as we did not yet have data on the frequency of use of anche, aussi and also in written texts.

\begin{tabular}{|l|l|l|l|}
\hline & NF$^{20}$ & AF & Text searched \\
\hline Anche & $\mathbf{3 8 0}$ & 922 & 242500 \\
\hline Aussi & $\mathbf{1 0 6}^{21}$ & 278 & 263000 \\
\hline Also & $\mathbf{1 6 2}$ & 399 & 247000 \\
\hline
\end{tabular}

Table 3: Frequency of anche, aussi, also in a corpus of online news.

The gap between the data from Italian, on the one hand, and from French and English, on the other hand, can be explained in a first step by taking into account other AFAs. The AFAs that ought to be considered are in particular Fr. également and E. too and as well. Moreover, because It. anche allows for a scalar reading that is not available to Fr. aussi and E. also, we should also take into account French and English AFAs that are intrinsically scalar, such as Fr. même and E. even. Here are three examples that illustrate the fact that It. anche is semantically less constrained and thus more frequent than Fr. aussi and E. also (these examples are taken from De Cesare/Borreguero Zuloaga 2014: 63-64):

(39) È un sistema educativo molto democratico che non esclude a priori nessun candidato. Anche (= perfino) il meno preparato degli studenti potrà accedere all'esame.

(40) C'est un système éducatif très démocratique qui n'exclue en principe aucun candidat. Même le moins préparé des étudiants [*aussi] pourra accéder à l'examen.

(41) It's a very democratic education system; none of the candidates is in principle excluded. Even the least prepared of the students [*also] will have access to the exam.

In order to understand to what extent the lower frequency of Fr. aussi and E. also in respect to It. anche results from the availability of other AFAs, we have taken a look at the frequency of use of a series of alternative AFAs in the French and English parts of our work corpus. The results, given as normalized frequencies (over 100000 words) are as follows: ${ }^{22}$

\footnotetext{
20 In this and the following tables, the abbreviation NF stands for "normalized frequency", which is a figure measured on 100000 words; in turn, the abbreviation AF stands for "absolute frequency", which corresponds to the actual number of occurrences found in the corpus. Several tables below also contain the abbreviation RF, which stands for "relative frequency" and coincides with a percentage.

21 This figure is strikingly similar to the one given by Blumenthal 1985 on the basis of an analysis of a paper edition of Le Monde (the issue is from the 4.1.1984). In Blumenthal's corpus, aussi occurs 11 times in 10000 words (specifically, it occurs 46 times in 42027 words).

22 Not considered here are all the uses of these items as non-AFAs, i.e. as conjunctions or connectives (Fr. même si, quand (bien) même, avant même, de même (que), tout de même, alors même; E. even if/though and as well as), adjectives (Fr. le même 'the same', E. We've got to break even) or intensifiers (too high). Also discarded from the data given in Table 4 are all the uses of these items as negative AFAs, i.e. as AFAs occurring in a context associated to negative polarity (i.e. Fr. sans/pas même, E. not even).
} 


\begin{tabular}{|c|c|c|c|c|c|}
\hline & \multicolumn{2}{|c|}{ Additive AFAs } & \multicolumn{2}{c|}{ Scalar AFAs } & Text searched \\
\hline French & également & $\mathbf{5 7}$ & même & $\mathbf{4 9}$ & 263000 \\
\hline English $^{23}$ & too & $\mathbf{1 8}$ & even & $\mathbf{6 0}$ & 247000 \\
& as well & $\mathbf{7}$ & & & \\
\hline
\end{tabular}

Table 4: Frequency of French and English secondary AFAs in a corpus of online news.

As we can see from the data provided in Table 4, even if we take into account other French and English AFAs, we do not arrive at the frequency of It. anche: summing up the normalized frequencies of aussi, également and même, we arrive at a total of $212 \mathrm{occ} . / 100000$, still well below the 380 occ. of It. anche. The same holds true for English: the sum of the normalized frequencies of also, too, as well and even in the corpus amounts to a total of $247 \mathrm{occ} . / 100000$. Comparing the new data from French and English, we can observe that the results are quite similar (212 occ. in French and 247 occ. in English).

The explanation for the gap between It. anche, on the one hand, and Fr. aussi as well as E. also, on the other, is of course very partial and indicative, since a thorough explanation of the asymmetry between these AFAs should also include a quantitative analysis of negative AFAs (Fr. non ... plus, E. (n)either, nor, not even) as well as other positive AFAs (such as for instance E. likewise and similarly). Moreover, it is clear that our explanation ought to be based on a fine-grained qualitative analysis of all the forms that could potentially be used. Clearly, more research ought to be done on this point in the future, in particular by relying on a parallel (i. e. translation) corpus of written texts.

\subsubsection{Frequency of anche, aussi, also in canonical word orders}

In this section, we report on the frequency with which It. anche, Fr. aussi and E. also occur in canonical sentence patterns, i. e. in SV/SVO/SVOO words orders. The syntactic patterns considered as canonical are sentences based on a simple or a complex verb form, with transitive or intransitive verbs. The abbreviation $O$ should be understood as any type of argument of the verb that normally follows it (i. e. Direct object, Indirect object, Prepositional object etc.). It should be added that we took into account the occurrences of anche, aussi and also in both main and subordinate clauses and that we have decided to also count their instances in correlative structures such as It. non solo... ma anche; Fr. pas seulement... mais aussi, E. not only... but also.

By contrast, not included in our analysis are all the configurations in which anche, aussi and also have scope over an adjunct (adverbial of time, space etc.), as in (42). Also excluded are the cases in which our AFAs do not have scope over a constituent placed in its canonical position, i. e. cases in which they focus on a preverbal constituent that does not correspond to the Subject, as in (43), and a postverbal constituent that does not coincide with the Direct object, as in (44), where also has scope over the postverbal Subject. ${ }^{24}$ Excluded from our

\footnotetext{
${ }^{23}$ Similar results are described in Taglicht (1984: 184-185). In a corpus of non-private writing, also is far more frequent than its alternatives (also: $86.7 \%$; too: $12.2 \%$; as well: $1.1 \%$ ).

${ }^{24} \mathrm{We}$ are of course aware of the fact that some VS patterns cannot really be defined as non-canonical (cf. Italian VS orders based on an inaccusative verb, such as è arrivata Maria 'Mary arrived'). However, in this study we decided to adopt a fairly narrow definition of canonical word order, and only include the cases in which the Subject is placed before the finite verb (note that in Italian the Subject can also be implicit).
} 
sample are also all the occurrences in which our AFAs appear in nominal clauses such as (45), where no finite verb is present. All the following examples are from the English corpus, but in all the cases parallel structures are found mutatis mutandis in the Italian and French sub-corpora as well.

(42) In 2006 Walliams swam the Channel, raising £1m in aid of Sport Relief. He has also swum the strait of Gibraltar, and last year cycled from John O'Groats to Land's End, also for Sport Relief. (ICOCP, theguardian.uk)

(43) Also on sale is a small oil painting of the queen with her favourite Scottish ghillie, John Brown, [...] (ICOCP, theguardian.uk)

(44) Private guards do not have the authority to make arrests other than citizens' arrests, cannot pursue fleeing suspects, make DWI arrests or even traffic stops. There's also the issue of whether self-incriminating statements or evidence taken from a suspect by a security officer could be used in court, she wrote. (ICOCP, usatoday.com)

(45) What also of My Lady Dedlock? (ICOCP, theguardian.uk)

On the basis of a sample of 300 occurrences of It. anche, Fr. aussi and E. also (we took into account the first 100 occ. appearing in our data collection for each language ${ }^{25}$ ) we measured the frequency with which these AFAs occur in canonical sentences, i. e. in clauses with $\mathrm{SV} / \mathrm{SVO} / \mathrm{SVOO}$ words orders. The results are listed in the following table:

\begin{tabular}{|l|c|}
\hline & $\mathrm{RF}$ \\
\hline anche & $42 \%$ \\
\hline aussi & $82 \%$ \\
\hline also & $90 \%$ \\
\hline
\end{tabular}

Table 5: Relative frequency of anche, aussi and also in canonical word orders.

This data show that there are major cross-linguistic differences between the syntactic configurations in which the three AFAs appear. On the basis of the number of tokens given in Table 5, we can observe that It. anche occurs in a canonical sentence in less than half of the cases analyzed, whereas Fr. aussi and E. also appear in a canonical sentence in most of their occurrences. Here, of course, the asymmetry between Italian, on the one hand, and the other two languages, on the other, is fully expected and can be explained on the basis of the higher degree of freedom with which Italian can arrange its main sentence constituents compared to French and English. As several options are possible, less predictable was the configurations in which anche, aussi and also have the Subject as their DA (cf. Table 1).

\subsection{Anche, aussi, also with the canonical Subject as domain of association}

\subsubsection{Subject vs. other types of domain of association}

In order to determine how frequently It. anche, Fr. aussi and E. also have the Subject of a canonical sentence as their DA, we distinguish two configurations: (i) the cases in which they have the canonical Subject as DA and (ii) all the other cases. In the second category, the three

25 This is of course a rather small sample and the results presented here are thus to be regarded as preliminary. 
AFAs can be associated with the verb, an Object (Direct, Indirect or Prepositional) or the whole VP. Table 6 provides the relative and absolute frequencies of the two configurations.

\begin{tabular}{|l|c|c|c|c|c|}
\hline & \multicolumn{2}{|c|}{ Subject } & \multicolumn{2}{c|}{ V/O/VO/VOO } & Total \\
\hline & RF & AF & RF & AF & AF \\
\hline anche & $\mathbf{3 1 \%}$ & 13 occ. & $\mathbf{6 9 \%}$ & 29 occ. & 42 \\
\hline aussi & $\mathbf{8 \%}$ & 7 occ. & $\mathbf{9 1 \%}$ & 75 occ. & 82 \\
\hline also & $\mathbf{1 4 \%}$ & 13 occ. & $\mathbf{8 6 \%}$ & 77 occ. & 90 \\
\hline
\end{tabular}

Table 6: Domain of application of anche, aussi and also in canonical word orders.

The data contained in Table 6 show that, in most of the occurrences in which anche, aussi and also occur in a canonical sentence, they modify the predicate or part of it. This fact of course highlights that this configuration is prototypical. Thus, overall, when it comes to identifying the main DA of our AFAs, the three languages behave quite similarly. In the following examples, anche, aussi and also have scope over the Object:

(46) Quello che l'agenzia matrimoniale (o meglio "Club per single", secondo la nuova moda) "Il Delfino" fa, non è per tutti. Aiuta gli omosessuali a trovare un compagno e, se la ricerca va a buon fine, ad accompagnarli all'altare. [...] L'agenzia organizza anche sedute di coaching e incontri "SosSolutudine", per aiutare chi ancora non ha fatto coming out. (ICOCP, corriere.it)

Lit. '[...] The agency organizes also coaching sessions and meetings "SosLoneliness".'

(47) Refermée sur elle-même, la Corée du Nord subit des déficits commerciaux depuis plus de 20 ans malgré les richesses de ses sous-sols. Le pays souffre aussi de pénuries alimentaires chroniques. (ICOCP, lefigaro.fr)

Lit. '[...] The country suffers also from chronic food shortages.'

(48) Ten months after she was shot through the left side of her brain at a constituent event near Tucson, a crazed shooting in which six people died, Giffords wants to go back to her seat in the House of Representatives.

She also wants to have a baby [...] (ICOCP, usatoday.com)

The data provided in Table 6 also show that the three languages do not behave along the same lines. Selecting the canonical Subject as their DA is much more marginal for Fr. aussi and E. also (these AFAs do so in only $8 \%$ and $14 \%$ of the cases, respectively). By contrast, It. anche selects the canonical Subject as its DA in roughly a third of the cases in which we find it in a canonical clause. ${ }^{26}$

Another difference between the three languages analyzed regards the syntactic configurations in which our AFAs select the canonical Subject as their DA. It. anche always occurs in the configuration 'anche $\underline{\mathrm{S}} \mathrm{V}_{\text {fin' }}$ (13 occ. out of 13), as in (49) below. Thus, Italian resorts to a pattern that unequivocally points to the association of anche with the canonical Subject.

\footnotetext{
${ }^{26}$ The closer association of Italian anche with the Subject could be expected to be even higher if we were to consider the cases in which the Subject is found after the verb, i. e. if we had taken into account non-canonical sentence patterns.
} 
(49) Dopo la Germania, anche gli Stati Uniti vedono scendere il tasso di disoccupazione che a novembre è risultato pari all' $8,6 \%$ dal $9 \%$ di ottobre. (ICOCP, corriere.it)

'After Germany, the United States, too, experience the unemployment rate go down.'

In English, also takes the Subject as its DA in two distinct configurations. In the first one, which is the most frequent in our data (we find it in 9 out of 13 occ.), also occurs in postadjacent position to the Subject, in the pattern ' $\underline{\mathrm{S}}$ also $\mathrm{V}_{\text {fin', }}$, as in (50). In the second configuration, also occurs after the finite verb, in the pattern 'S $\mathrm{V}_{\text {fin }}$ also', as in (51). Note that in our corpus sample also associated to the canonical Subject tends to precede a simple verb form (50) and follow a complex one (51).

By all accounts, Halman maintained a strong relationship with his family. His father, Eddy, was a professional baseball player in the Netherlands. His older sister, Naomi, plays professional basketball in Italy. His brother also played professionally in the Netherlands, and VandenHurk said the two were "as close as brothers can be." (ICOCP, nytimes.com)

(51) "The bulk of our middle class are retirees who came from New York or New Jersey, and they retired on fixed incomes and investments," says Mayor Lee Wilson Bettis.

Those investments have suffered because of the volatile stock market, and many of those retirees have had to go back to work, he says.

At the same time, the area's job base, made up in part of manufacturing and trucking, has also been hurt, he says. Large companies such as Hatteras Yachts, which makes luxury boats, and BSH Home Appliances, which makes high-end appliances, have cut hundreds of jobs. (ICOCP, usatoday.com)

In selecting the canonical Subject as its DA, Fr. aussi is the most peculiar of the three AFAs. First, as pointed out above, aussi only marginally takes the canonical Subject as its DA ( $8 \%$ of the occurrences). Second, in the cases in which it takes the canonical Subject as its DA, aussi is never adjacent to it. A rare case, found outside the corpus sample analyzed (i. e. of our 100 occ. of aussi), is given in (52). The fact that our corpus does not contain any occurrence of aussi placed between the Subject and the finite verb is partly surprising, since this is one of the positions in which the AFA unequivocally selects the Subject as its DA and is reported as being fairly natural. Our data thus strongly deviate from other findings reported in the literature (in Lauwers' 2003 data, aussi is found in the configuration ' $\underline{\mathrm{S}}$ aussi $\mathrm{V}_{\text {fin }}$ ' in $55 \%$ of the cases in which it selects the Subject as its $\mathrm{DA}^{27}$ ).

(52) Si la fondation vient en aide à de nombreux chiites, majoritaires dans le Sud, Rabab Sadr, comme jadis son frère, rejette toute démarche sectaire: "Nous travaillons pour tous, sans distinction. Quand nous plaidons pour les droits des femmes, auxquels l'Etat ne s'intéresse pas, c'est pour toutes les Libanaises !" Des critiques ou mots

\footnotetext{
27 We may wonder if the pattern ' $\underline{S}$ aussi $\mathrm{V}_{\text {fin }}$ ' reported in Lauwers 2003 could, at least partly, be explained as being the result of a calque from Dutch and be thus due to his choice of analyzing data from a parallel corpus Dutch-French. This explanation is not fully satisfactory though, as, in contrast with Fr. aussi, D. ook must precede the Subject (*Jan ook is vertrokken 'John also left', ex. from Lauwers 2003: 10; see also the data proposed in Dimroth/Benazzo, in this issue).
} 
méprisants qui volent parfois encore à l'encontre des chiites, aujourd'hui influents, cette femme respectée pense qu'ils "s'estomperont avec le temps. Les chiites aussi ont le droit de participer au pouvoir. Le Liban est pour tout le monde". (ICOCP, lemonde.fr)

' "[...] The Shiites too have the right to participate to the power. Libanon is for everybody".'

In our small corpus sample, Fr. aussi focuses on the Subject in two distinct configurations. In a first pattern (found in 2 out of a total of $7 \mathrm{occ}$.), illustrated in (53) and (54), aussi occurs after the finite verb form, in the configuration ' $\underline{\mathrm{S}} \mathrm{V}_{\text {fin }}$ aussi'. In the second example given below, aussi is even placed after the past participle, i. e. is found in a configuration that (out of context) would favor the Direct object leur petit tour as aussi's DA.

(53) Les sous-sols de la Corée du Nord sont notamment d'une grand [sic] richesse. Le pays regorge de fer, magnésite, phosphate, mercure, argent ou encore titane. Les métaux non ferreux (zinc, plomb) sont aussi très présents. (ICOCP, lefigaro.fr)

'North Korea's subsoil is very rich. The country is full of iron [...]. Non-iron metals (zinc, lead) are also very present.'

(54) Côté intello, le festival d'Avignon est "le" rendez-vous obligé de l'été 2011. Un à un, les candidats aux primaires socialistes y défilent et flattent les artistes dans le sens $d u$ poil. On a même entendu Martine Aubry, qui rêvait d'être ministre de la Culture avant de viser l'Élysée, promettre une augmentation de 30 à $50 \%$ du budget de la Culture. François Hollande, lui aussi en visite dans la cité des Papes, a tout de suite mis en garde contre la "surenchère". Les autres candidats du PS, Arnaud Montebourg et Manuel Valls, avaient fait aussi leur petit tour. (ICOCP, lefigaro.fr)

'[...] The Avignon Festival is "the" big event of the summer 2011. One by one, the candidates to the socialist primaries come here [...]. François Hollande, he also on a visit the Pope's city, [...]. The other candidates of the PS, Arnaud Montebourg and Manuel Valls, have also paid a visit.'

In the second configuration in which the French AFA has the Subject of a canonical sentence as its DA (found in 5 out of 7 occ.), aussi occurs in the special syntactic pattern in which the Subject is reduplicated by a full pronoun, i. e. in the configuration ' $\underline{S}_{i} \mathrm{~V}_{\text {fin }} \underline{\text { pro }}_{i}$ aussi' (cf. $\S$ 3.3). Here is an example from our corpus:

(55) L'attaquant français était remplaçant face à l'Udinese et n'est pas rentré en jeu. Philippe Mexès a disputé l'intégralité du match Milan AC-Sienne (voir le joueur du week-end). Sébastien Frey était titulaire dans les buts du Genoa avec une victoire à la clé 2-1 face à Bologne. Jonathan Biabiany $\underline{i}_{\mathbf{~}} \underline{\mathbf{l u}}_{\mathbf{i}}$ aussi joué 90 minutes avec Parme, tenu en échec face à Lecce dans un match un peu fou (3-3). (ICOCP, lefigaro.fr)

Lit. 'Jonathan Biabiany has he also played 90 minutes with Parma.' 


\subsubsection{Canonical Subject as domain of association: overview of cross-linguistic options}

Table 7 provides a detailed overview of the frequency with which anche, aussi and also select the canonical Subject as their DA in the syntactic configurations claimed to be at their disposal in the current literature (cf. Table 1, where the results are given as percentages).

\begin{tabular}{|l|l|c|c|c|}
\hline & & It. anche & Fr. aussi & E. also \\
\hline I & AFA $\underline{S} V_{\text {fin }}(\mathrm{O})$ & $\mathbf{1 0 0 \%} / \mathrm{NS}$ & NA & NA \\
\hline II & $\underline{S}$ AFA $V_{\text {fin }}(\mathrm{O})$ & $0 / \mathrm{NS}$ & $0 / \mathrm{NS}$ & $\mathbf{6 9 \%} / \mathrm{WS}$ \\
\hline III & $\underline{\mathrm{S}} \mathrm{V}_{\text {fin }}$ AFA (O) & $0 / \mathrm{WS}$ & $\mathbf{2 9 \%} / \mathrm{WS}$ & $\mathbf{3 1 \%} / \mathrm{WS}$ \\
\hline IV & $\underline{\mathrm{S}} \mathrm{V}_{\text {fin }} \mathrm{O}$ AFA & $0 / \mathrm{WS}$ & $0 / \mathrm{WS}$ & $0 / \mathrm{WS}$ \\
\hline V & Subject reduplication & $0 / \mathrm{NS}$ & $\mathbf{7 1 \%} / \mathrm{NS}$ & NA \\
\hline
\end{tabular}

Table 7: Configurations in which anche, aussi and also select the canonical Subject as DA.

This data show in more detail that, when it comes to selecting the Subject as their DA, It. anche, Fr. aussi and E. also behave quite differently. First, while Italian resorts to only one configuration (left adjacency of anche to its DA), French and English resort to two. Second, there is hardly any overlap between the configurations actually selected in the corpus by the three languages: Italian opts for configuration I, French for III and V and English for II and III. Thus, only configuration III is common to two languages, i. e. to French and English. Note here how similar the two languages are in this case, both from a quantitative and a qualitative point of view. In both languages this configuration occurs in roughly a third of all instances and the AFA occupies a wide scope position, i. e. a position in which it can select different constituents as DA (among others, the Subject).

A common feature of Italian and French is the selection, as the preferred option, of the most transparent way of expressing that the Subject is the AFA's DA: in Italian, it is configuration I, while in French configuration V. In English, as we saw already on the basis of Table 1, narrow scope position involving the canonical Subject is not available to also. This leads to the observation that in English narrow scope over the canonical Subject is in fact achieved by another AFA, namely too (Rideout 1995: 113; Gast 2006: 171). Consider example (56), in which too appears in configuration II, i. e. is placed between the Subject (she) and the finite verb (noticed). While the use of also in the same context would lead to a strong contextdependency in the interpretation of the Subject as its DA (as it could refer to the Subject but also to the Predicate or part of it), too unequivocally indicates that the preceding Subject is its DA because too is right-adjacent to its DA. Example (57) even shows that the AFA too can occur between the pronoun it and the main finite verb, a position that seems more restricted to also ( ${ }^{?}$ it also has...).

(56) Ms. McGary's realization was part of a storm that blew through the blogosphere. It started when a few people started to see their Klout scores rise and fall and - what else? - began posting on Twitter about it.

In Montauk, N.Y., Tonia Ries clicked on her Klout page one morning to check out what the fuss was about. She too noticed her son, Timothy Carson, pop up on her page, with a Klout score assigned to him and a link to his Facebook page. (ICOCP, nytimes.com) 
(57) Barnes \& Noble, on the other hand, offers the convenience of human tech support in its 700 stores. It, too, has an Android-based tablet in the wings; I'll review it when it's available. (ICOCP, nytimes.com)

Additional remarks ought to be made on the basis of the configurations that have not been found in the corpus. Out of the different options that are reported to be available in spoken (elicited) speech (see again Benazzo/Andorno 2010 and Dimroth et al. 2010), not all the options allowing for the selection of the canonical Subject as the AFAs' DA are actually realized in our corpus sample. This can certainly be explained on the basis of the small size of our corpus (100 occ. for each AFA). As we have seen for instance with example (52), there are in fact cases in which Fr. aussi occurs in configuration II in our general corpus as well (i. e. beyond the 100 occ. analyzed). The same claim can be made on configuration $\mathrm{V}$ in Italian. ${ }^{28}$ As shown in (58), we find examples of the configuration with Subject reduplication in journalistic prose:

(58) "Abbiamo - ha detto - ancora otto anni di vantaggio, prima che la China abbia anche lei la sua stazione spaziale [...]." (ICOCP, repubblica.it)

Lit. 'We still have - he said - eight years of advantage, before China has also she her space station.'

By taking a closer look at the case reported in (58), it is possible to give another explanation for the absence of configuration V in our Italian corpus sample: in contemporary Italian, there is a gap in the pronominal system to refer to unanimated referents (Andorno 2006: 129-131). While the personal forms lui/lei are not easily compatible with an unanimated referent (example (58) could be perceived as being slightly odd), pronominal forms such as esso/essa are considered to be archaic. In French, by contrast, it is absolutely natural to refer to an unanimated referent with the personal pronouns lui/elle. Consider the two following examples, where the masculine lui refers to an airplane and the feminine elle to an old town. Again, an Italian translation of these examples with the pronouns lui and lei, respectively, would be odd at best:

(59) [...] l'an passé un Boeing 747-400 avait lui aussi été immobilisé après une grande visite en Chine (ICOCP, lemonde.fr)

Lit. '[...] last year a 747-400 Boeing had he also been immobilized after an important visit in China' = 'last year a 747-400 Boeing had also been immobilized after an important visit in China'

(60) La vieille ville, en particulier le quartier chinois, a elle aussi été sévèrement inondée (ICOCP, lemonde.fr)

Lit. 'The old town, in particular the Chinese neighborhood, had she also been severely flooded' = 'The old town, in particular the Chinese neighborhood, was also severely flooded'

\footnotetext{
${ }^{28}$ Interestingly, Fr. aussi can be left-adjacent to its DA when the predicate is elliptical. Consider the following example: "L'émetteur a sa part de responsabilité mais aussi le récepteur" (ICOCP, lefigaro.ch), Lit. "The transmitter has its share of responsibility but also the receiver".
} 
Finally, missing configurations from our corpus can also be explained by another factor, namely by their tight connection with informal, spoken speech. This, in our view, explains in particular the absence of configuration IV in the Italian data. ${ }^{29}$

\section{$5 \quad$ Concluding remarks}

On the basis of a comparable corpus of written online news, this study confirms one of the most important findings pointed out in other cross-linguistic analyses, conducted on a partly different set of AFAs and on partly different data. While sharing basic semantic and syntactic features, the most commonly occurring AFAs present major differences, which will be recalled below, along with some of the questions that remain open.

First, It. anche, Fr. aussi and E. also differ quite significantly in their overall frequency of use, anche being by far the most frequently occurring adverb of the three. This finding, which was already pointed out in the literature for It. anche and Fr. aussi, surely ought to be explained by the fact that anche is semantically less constrained than the other two AFAs, as it is compatible with a scalar reading. In order to throw more light on the asymmetry in the frequency of use of anche, on the one hand, and aussi and also, on the other, more research is needed on three additional classes of AFAs: (i) less commonly occurring positive AFAs, such as Fr. également, E. too and as well; (ii) AFAs which are intrinsically scalar, such as Fr. même and E. even; (iii) negative AFAs, such as Fr. non plus, même pas and E. (n)either, nor, not even. Besides the semantic differences regarding the compatibility of our AFAs with a scalar reading, there might still be other reasons behind the low frequency of Fr. aussi and E. also. According to Blumenthal's 1985 study, for instance, Fr. aussi is less inclined than other AFAs (specifically than G. auch) to signal identity relations between text segments (in particular between words). Moreover, to be used properly, Fr. aussi requires in general ("exige en général") that the alternatives are given in the context (cf. Blumenthal 1985: 149). Finally, aussi might be sensitive to certain information features (Lauwers 2003: 11). Thus, both information structure and discourse patterns ought to be taken into account more systematically in future research.

Second, by focusing our attention on a non-prototypical configuration, i. e. the cases in which It. anche, Fr. aussi and E. also are associated with the preverbal Subject (i. e. introduce a new entity, while signaling that the rest of the sentence should hold for at least one other entity), we observe major differences between the three AFAs. The cross-linguistic differences arising in this particular configuration are certainly enhanced by the choice of our object of study: as already acknowledged on several occasions, in non-prototypical situations, languages resort to more differentiated strategies. This is true in particular for French and English.

In closing this paper, we would like to underline that the three languages analyzed, i. e. Italian, French and English - do not always pattern along genetic groups. In several instances it has been shown that Fr. aussi is closer to E. also than to It. anche. With respect to what is found by Dimroth/Benazzo (this issue) on the basis of Italian, French, German and Dutch

\footnotetext{
${ }^{29}$ Note that this finding is perfectly in line with the results described in De Cesare 2004b on the basis of the CORIS corpus; this study shows that in written Italian, anche is fairly marginally found in sentence final position.
} 
data, our study - which only considers in detail one of the two configurations analyzed in Dirmoth/Benazzo (this issue) - thus does not confirm that the differences highlighted can be explained in typological terms alone.

\section{References}

Amsili, Pascal/Winterstein, Grégoire (2012): "Les déclencheurs de présupposition additifs". Langages 186/2: 85-100.

Andorno, Cecilia (1999): "Avverbi focalizzanti in italiano. Parametri per un'analisi". Studi Italiani di Linguistica Teorica e Applicata 28/1: 43-83.

Andorno, Cecilia (2000): Focalizzatori fra connessione e messa a fuoco. Il punto di vista delle varietà di apprendimento. Milano: FrancoAngeli.

Andorno, Cecilia (2005): "Additive and restrictive particles in Italian as a second language. Embedding in the verbal utterance structure". In: Hendriks, Henriëtte (ed.): The Structure of Learner Varieties. Berlin/New York, de Gruyter: 405-444.

Andorno, Cecilia (2006): "Accordo di genere e animatezza nell'uso del sistema pronominale italiano: ipotesi per uno studio". In: Luraghi, Silvia/Olita, Anna (eds.): Linguaggio e genere. Roma, Carocci: 124-154.

Andorno, Cecilia (2008): "Ancora su anche, anche su ancora. Per uno studio comparativo dell'apprendimento e della gestione di strategie coesive in IL". In: Lazzeroni, Romano et al. (eds.): Diachronica et Synchronica. Studi in onore di Anna Giacalone Ramat. Pisa, ETS edizioni: 29-52.

Andorno, Cecilia/Turco, Giuseppina (2015): "Embedding additive particles in the sentence information structure: How L2 learners find their way through positional and prosodic patterns". Linguistik online 71, 2/2015: 57-79.

Benazzo, Sandra/Andorno, Cecilia (2010): "Discourse cohesion and Topic discontinuity in native and learner production. Changing topic entities on maintained predicates". EUROSLA Yearbook 10: 92-118.

Benazzo, Sandra/Dimroth, Christine (2015): "Additive particles in Romance and Germanic languages: Are they really similar?". Linguistik online 71, 2/2015: 9-30.

Blumenthal, Peter (1985): "Aussi et auch: deux faux amis?". Französisch heute 2: 144-150.

Borreguero Zuloaga, Margarita (2011): "Focalizzatori a confronto: anche vs también". Studi italiani di linguistica teorica e applicata XL/3: 441-468.

Calaresu, Emilia Maria (2004): Testuali parole. La dimensione pragmatica e testuale del discorso riportato. Milano: FrancoAngeli.

Combettes, Bernard/Tomassone, Roberte (1988): Le texte informatif, aspects linguistiques. Bruxelles: De Boeck-Wesmael.

Dardano, Maurizio (1994): "Profilo dell'italiano contemporaneo". In: Serianni, Luca/Trifone, Pietro (eds.): Storia della Lingua italiana, vol. II [Scritto e parlato]. Torino, Einaudi: 343430.

Dardano, Maurizio (2008): "Tra innovazione e conservazione". In: Dardano, Maurizio/Frenguelli, Gianluca (eds.): L'italiano di oggi. Roma: Aracne.

De Cesare, Anna-Maria (2004a): "L'avverbio anche e il rilievo informativo del testo". In: Ferrari, Angela (ed.) (2004): La lingua nel testo, il testo nella lingua. Torino, Istituto dell'Atlante Linguistico Italiano: 191-218. 
De Cesare, Anna-Maria (2004b): "Y a-t-il encore quelque chose à ajouter sur l'italien anche? Une réponse basée sur le CORIS/CODIS". Rivista di linguistica/Italian Journal of Linguistics 16/1: 3-34.

De Cesare, Anna-Maria (2008): "Gli avverbi paradigmatizzanti". In: Ferrari, Angela et al.: L'interfaccia lingua-testo. Natura e funzioni dell'articolazione informativa dell'enunciato. Alessandria, Edizioni dell'Orso: 340-361.

De Cesare, Anna-Maria (2010): "On the focusing function of focusing adverbs. A discussion based on Italian data". Linguistik online 44/4: 99-116.

De Cesare, Anna-Maria/Borreguero Zuloaga, Margarita (2014): "The contribution of the Basel Model to the description of polyfunctional discourse markers. The case of It. anche, Fr. aussi and Sp. también". In: Pons Bordería, Salvador (ed.): Discourse Segmentation in Romance Languages. Amsterdam/Philadelphia, John Benjamins: 55-94. (= Pragmatics and Beyond New Series 250).

De Cesare, Anna-Maria et al. (2014): "Form and frequency of Italian cleft constructions in a corpus of electronic news. A comparative perspective with French, Spanish, German and English". In: De Cesare, Anna-Maria (ed.): Frequency, Forms and Functions of Cleft Constructions in Romance and Germanic. Contrastive, Corpus-based Studies. Berlin/New York, de Gruyter: 49-99. (= Trends in Linguistics 281).

De Cesare, Anna-Maria (in press): "Defining Focusing Modifiers in a cross-linguistic perspective. A discussion based on English, German, French and Italian". In: Pittner, Karin/Elsner, Daniela/Barteld, Fabian (eds.): Adverbs - Diachronic and Functional Aspects. Amsterdam-Philadelphia: John Benjamins. (= Studies in Language Companion Series).

Dimroth, Christine/Klein, Wolfgang (1996): "Fokuspartikeln in Lernervarietäten. Ein Analyserahmen und einige Beispiele". Zeitschrift für Literaturwissenschaft und Linguistik 104: 73-114.

Dimroth, Christine et al. (2010): "Given claims about new topics. How Romance and Germanic speakers link changed and maintained information in narrative discourse". Journal of Pragmatics 42: 3328-3344.

Fjelkestam-Nilsson, Brita (1983): Also and Too. A Corpus-based Study on their Frequency and Use in Modern English. Stockholm: Almqvist and Wiksell.

Gast, Volker (2006): "The distribution of also and too - a preliminary corpus study". Zeitschrift für Anglistik und Amerikanistik 54/2: 163-176.

Gualdo, Riccardo (2007): L'italiano dei giornali. Roma: Carocci.

Huddleston, Rodney D./Pullum, Geoffrey K. (2002): The Cambridge Grammar of the English Language. Cambridge: Cambridge University Press.

König, Ekkehard (1991): The Meaning of Focus Particles: A Comparative Perspective. London/New York: Routledge.

König, Ekkehard (1993): "Focus Particles". In: Jacobs, Joachim et al. (eds.): Syntax. Ein internationales Handbuch zeitgenössischer Forschung/An international Handbook of Contemporary Research. Vol. 1. Berlin/New York, de Gruyter: 978-987.

La Forgia, Francesca (2006): "Alcune osservazioni sui focalizzatori". Studi italiani di linguistica teorica e applicata 35/2: 359-385.

Lauwers, Peter (2003): "Aussi vs ook. Une étude contrastive de deux 'faux-amis"'. Leuven, Preprint 201, KULeuven: Dept. Linguistiek. 
Lauwers, Peter (2006): "Aussi vs. ook. Une analyse contrastive de deux adverbes polyfonctionnels". In: Mourón Figueroa, Cristina/Moralejo Gárate, Teresa (eds.): Studies in Contrastive Linguistics. Proceedings of the 4th International Contrastive Linguistics Conference. Santiago de Compostela, Universidade de Santiago de Compostela: 479-491.

Lepri, Sergio (2011): News. Manuale di linguaggio e di stile per l'informazione scritta e parlata. Milano: Rizzoli Etas.

McLaughlin, Mairi (2012): "L'oralisation et le discours rapporté dans les dépêches d'agences de presse". Le Discours et la langue 2/2: 89-98.

Nølke, Henning (1983): Les adverbes paradigmatisants: Fonction et analyse. Copenhagen: Akademisk Forlag.

Perrin-Naffakh, Anne-Marie (1996): "Aussi adjonctif: de la syntaxe à la sémantique". Le français moderne 64/2: 136-154.

Quirk, Randolph et al. (1985): A Comprehensive Grammar of the English Language. London: Longman.

Ricca, Davide (1999): "Osservazioni preliminari sui focalizzatori in italiano". In: Dittmar, Norbert/Giacalone Ramat, Anna (eds.): Grammatica e discorso. Studi sull'acquisizione dell'italiano e del tedesco. Tübingen, Stauffenburg: 146-164.

Rideout, Douglas (1995): "The notion of inclusion in the adverbs too and also". Dialangue 6: 113-116.

Taglicht, Josef (1984): Message and Emphasis. On Focus and Scope in English. London: Longman.

Ureña Gómez-Moreno, Pedro (2009): Los focalizadores del inglés: análisis morfosintáctico y semántico-pragmático de even $y$ also basado en corpus. Universidad de Granada: Departamento de Filologías Inglesa y Alemana, http://hera.ugr.es/tesisugr/17953005.pdf, accessed January 15, 2015. 